\title{
Allicin Reduces 5-fluorouracil-resistance in Gastric Cancer Cells through Modulating MDR1, DKK1, and WNT5A Expression
}

\author{
Authors \\ Parya Khakbaz', 2 (D), Reza Panahizadeh'1, 2 (D), Mohammad Amin Vatankhah', 2 (D), Nowruz Najafzadeh² (D)
}

Affiliations

1 Student Research Committee, School of Medicine, Ardabil University of Medical Sciences, Ardabil, Iran

2 Research Laboratory for Embryology and Stem Cells, Department of Anatomical Sciences, School of Medicine, Ardabil University of Medical Sciences, Ardabil, Iran

Key words

Gastric cancer, chemoresistance, allicin, 5-fluorouracil, CD44, P-glycoprotein

published online 14.07.2021

Bibliography

Drug Res 2021; 71: 448-454

DOI 10.1055/a-1525-1499

ISSN 2194-9379

(c) 2021. Thieme. All rights reserved.

Georg Thieme Verlag KG, Rüdigerstraße 14

70469 Stuttgart · Germany

\section{Correspondence}

Nowruz Najafzadeh, Ph.D., Associate Professor

Research Laboratory for Embryology and Stem Cells,

Department of Anatomical Sciences, School of Medicine,

Ardabil University of Medical Sciences

5618985991 Ardabil

Iran

Tel.: + 989104075700, Fax: + 984533534703

nowruz30@gmail.com

\section{ABSTRACT}

Background \& Objective 5-fluorouracil (5-FU) is approved for the treatment of gastric carcinoma (GC), but chemo-resistance limits the application of it for GC. Thus, the combination of 5-FU with adjuvants such as allicin may overcome multidrug resistance (MDR).

Methods The anticancer effects of allicin, 5-FU, and allicin/5FU on the 5-FU resistant MKN-45 cells were evaluated by MTT assay and DAPi staining. The expression of the P-glycoprotein (P-gp) and CD44 protein were determined using immunocytochemistry. We also quantified mRNA expression levels of WNT5A, Dickkopf-1 (DKK1), and MDR1 in the GC cells.

Results Here, we found that the combination of allicin with 5-FU significantly increased apoptosis compared to 5-FU alone $(P<0.05)$. We showed that WNT5A, MDR1, and DKK1 mRNA expression levels were down-regulated in the allicin- and allicin/5-FU-treated cells. Indeed, the combination of allicin and 5-FU significantly decreased the expression of the P-gp and CD44 proteins $(P<0.05)$.

Conclusion Our findings indicate that the combination of allicin with 5-FU could reverse multidrug resistance in the GC cells by reducing the expression of WNT5A, DKK1, MDR1, P-gp, and CD44 levels.

\section{Introduction}

Gastric cancer (GC) remained the most common cause of cancer mortality among men worldwide. The incidence rate is high in Western Asia countries, including Iran, Turkmenistan, and Kyrgyzstan. Helicobacter pylori infection, genetic changes, environmental factors, obesity, alcohol consumption, and tobacco smoking are the main risk factor for stomach cancer [1]. The highest prevalence rate has been reported in the northern region of Iran, Ardabil province [2].

GC is asymptomatic in the early stage. In advanced stages, it usually metastasizes to the lung, liver, peritoneum, and bone marrow. Although radical gastrectomy and chemotherapy are the main treatment options for GC to prolong the life of patients, the prognosis of GC patients has not been improved significantly [3]. 5-FU, as a thymidylate synthase inhibitor, blocks DNA synthesis and prevents cancer cell growth. Monotherapy with 5-FU elicits poor responses and the response rate is low (25-35\%). Thus, combination regimens with chemotherapeutics may have significant benefits in metastatic GC [4]. Although combination chemotherapy is commonly accepted for the treatment of GC, the efficacy of chemotherapeutics is limited due to chemoresistance and stem cell recurrence [5].

Prescription of 5-FU usually induces the expression of efflux pumps and the overexpression of DNA-repair mechanisms in cancer cells. The overexpression of $M D R, B C l-2, B c l-X L$, and $M c l-1$ genes and increased activation of thymidylate synthase and deoxyuridine triphosphatase mediates chemoresistance to 5-FU in many cancers [6]. In addition, Wnt pathway genes including Wnt5a and DKK1 in- 
volved in chemoresistance in several cancers. Wnt5a regulates G1-S transition and involved in chemoresistance in pancreatic cancer cells [7]. Overexpression of ALDH1A, REPS2, and DKK1 genes causes detoxification of drug agents and induces chemoresistance in colorectal cancer [8].

Several toxicities and side effects of 5-FU such as loss of appetite, hair loss, and skin inflammation [9] urged researchers to evaluate natural remedies against cancer.

Several garlic-derived compounds such as allicin, ajoene, diallyl trisulfide, and S-allylmercaptocysteine have potential anticancer activity. Allicin, the major component of garlic, has antibacterial, antiviral, and anticancer properties [10]. Previous studies have shown that allicin can sensitize chemotherapeutics against hepatocellular carcinoma [11], melanoma [12], osteosarcoma [10], and colorectal carcinoma [13] by inhibiting cell growth. Allicin inhibits proliferation in many cancers by activation of caspases, overexpression of Bax, and Fas induction of cytochrome $C$ release [14]. When the human lung, colorectal, and hepatocellular cancer cells were treated with both allicin and 5-FU, synergistic antitumor effects were observed [13,15].

However, whether allicin can sensitize chemoresistant GC to 5-FU is not clear. An innovative treatment perspective might be the use of allicin, particularly in combination with 5-FU, to re-sensitize cancer cells in the 5-FU resistant MKN-45 GC cell line. Here, we investigated whether the low doses of allicin could enhance the cytotoxicity of 5-FU and reduce the resistance of the cancer cells by regulating WNT5A, DKK1, MDR1, CD44, and P-gp expression level.

\section{Material \& Methods}

\section{Drugs}

5-FU (F6627) was purchased from Sigma-Aldrich. Dr. Mohsen Arzanlou (Ardabil, Iran) kindly provided allicin.

\section{Cell culture}

The human 5-FU resistant gastric cancer cell line MKN-45 was previously established by Pouremamali et al.[16] The GC cells were grown in RPMI1640 (Gibco, UK) medium supplemented with $10 \%$ fetal bovine serum (FBS, Gibco, UK), and $1 \%$ antibiotics.

\section{MTT assay}

The cell proliferation was evaluated with a standard MTT method. Briefly, $10^{4}$ cells/well were incubated overnight. The different concentrations of allicin $(2-64 \mu \mathrm{g} / \mathrm{ml}), 5-\mathrm{FU}(10-480 \mu \mathrm{g} / \mathrm{ml})$, and allicin/5-FU were used to treat the GC cells. Then, the cells were incubated in RPMI 1640 medium containing $5 \mathrm{mg} / \mathrm{ml}$ MTT (Sigma, M2128). The MTT solution was then replaced with $150 \mu$ of DMSO
(Scharlau Chemie). The absorbance values were determined by an ELISA reader.

\section{Nuclear morphology assay}

Briefly, the cells $\left(5 \times 10^{3}\right.$ cells/well) were grown in a 6 -well plate. Treated MKN-45 cells were fixed with $4 \%$ paraformaldehyde (PFA) at $4^{\circ} \mathrm{C}$ for $30 \mathrm{~min}$. Finally, the cells were stained with $1 \mu \mathrm{g} / \mathrm{ml} \mathrm{DAPi}$ in a dark room.

\section{Immunocytochemistry}

Immunofluorescence staining was used to determine the protein expression levels of P-gp and CD44 in the cancer cells. The cells were fixed with $4 \%$ PFA followed by incubation in normal goat serum and bovine serum albumin for $30 \mathrm{~min}$. Then, the cells were stained with the primary antibody against mouse anti-P-gp (1:150; sc-390883, Santa Cruz Biotechnology, Inc) for $2 \mathrm{~h}$ in dark. Next, cells were incubated with rat anti-mouse FITC secondary antibody (Thermo Fisher, 1: 200). The CD44 positive cells were detected with PE-conjugated mouse anti-human CD44 (1:150, Miltenyi Biotec, 130-095-180).

\section{Real-time PCR (RT-PCR)}

The mRNA level of DKK1, WNT5A, MDR1, and GAPDH was determined using RT- PCR as previously stated by Mokabber et al. [17]

Briefly, total RNA was extracted from the MKN-45 cell line using $1 \mathrm{ml}$ TRIzol (Invitrogen). First-strand complementary DNA (cDNA) was produced from $1 \mu \mathrm{g}$ total RNA using oligo $(\mathrm{dT})$ primer and M-MLV reverse enzyme (Vivantis, USA). oligo(dT, $1 \mu \mathrm{l}$ ) primer and nuclease-free water were mixed with mRNA, incubated at $65^{\circ} \mathrm{C}$ for $5 \mathrm{~min}$ and placed on ice for at least $1 \mathrm{~min}$. M-MuLV enzyme (100 u) and buffer $(10 \times)$ were added and incubated at $42^{\circ} \mathrm{C}$ for $60 \mathrm{~min}$ and then $85^{\circ} \mathrm{C}$ for $10 \mathrm{~min}$. Finally, qPCR was done with the SYBR Green PCR Master Mix (EURx, Ltd, Gdañsk, Poland). Real-time PCR reaction was performed in 3 steps: $95^{\circ} \mathrm{C}$ for $20 \mathrm{~s}$, followed by 40 cycles of $95^{\circ} \mathrm{C}$ for $5 \mathrm{~s}$, and $60^{\circ} \mathrm{C}$ for $5 \mathrm{~s}$.

The RT-PCR System (Roche Applied Science) was used to analyze gene expression. Specific human primers DKK1, WNT5A, MDR1, and GAPDH were designed using OLIGO 7.0 software. GAPDH gene was used as a reference gene and relative gene expression was calculated using the CT method $[18,19]$. Primer sequences were shown in $>$ Table 1.

\section{Statistics}

Data evaluation was performed using the SPSS software ver. 21. Statistical comparisons were made using the unpaired one-way ANOVA and Student's $t$-test.

- Table 1 List of primer sequences and product sizes used for RT-PCR analysis.

\begin{tabular}{|l|l|l|l|}
\hline Genes & Forward & Reverse & Product size \\
\hline DKK1 & TAGCACCTTGGATGGGTATT & ATCCTGAGGCACAGTCTGAT & 110 \\
\hline WNT5A & CGCCCAGGTTGTAATTGAAG & GCATGTGGTCCTGATACAAGT & 164 \\
\hline MDR1 & AGAGGGGATGGTCAGTGTTGA & TCACGGCCATAGCGAATGTT & 138 \\
\hline GAPDH & ACATCATCCCTGCCTCTACTG & CCTGCTTCACCACCTTCTTG & 180 \\
\hline
\end{tabular}



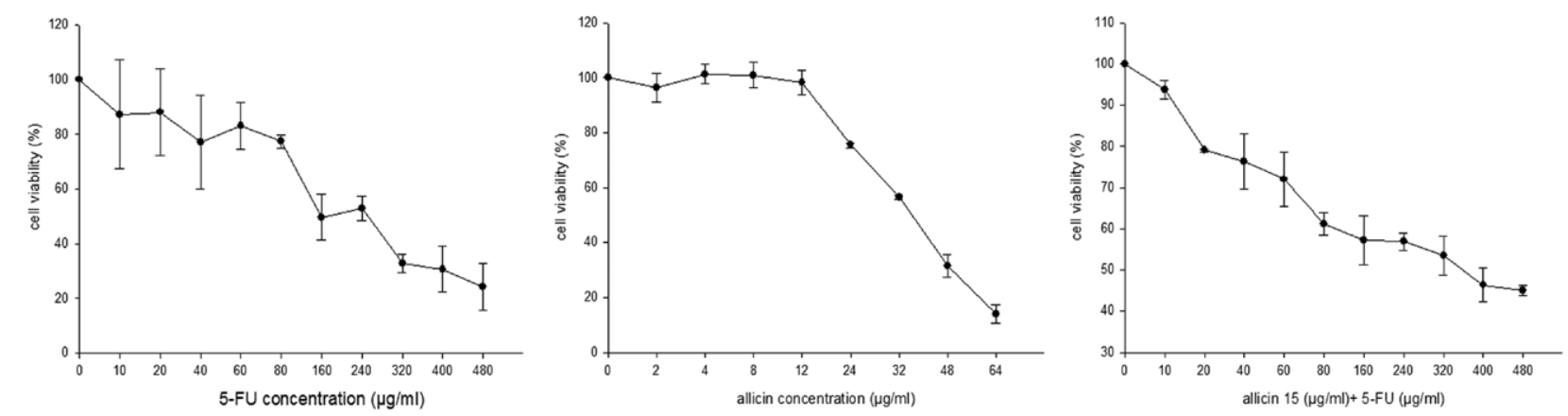

- Fig. 1 Cell growth inhibitory curves after treatment of cells with different concentrations of 5-FU (a), allicin (b), and their combination treatments (c).

- Table $2 \mathrm{IC}_{50}$ values represent the concentration of each drug that inhibits cell viability by $50 \%$.

\begin{tabular}{|l|c|}
\hline Groups & $\mathbf{I C}_{50}$ \\
\hline 5 -FU $(\mu \mathrm{g} / \mathrm{ml})$ & $164.52 \pm 1.92$ \\
\hline allicin $(\mu \mathrm{g} / \mathrm{ml})$ & $35.39 \pm 0.05$ \\
\hline allicin $(\mu \mathrm{g} / \mathrm{ml})+5$-FU & $49.46 \pm 10.61^{*}$ \\
\hline${ }^{*} P<0.05$ compared to 5-FU alone. \\
\hline
\end{tabular}

\section{Results}

\section{Low doses of allicin enhance the cytotoxicity of 5-FU against 5-FU resistant gastric cancer}

The anticancer activities of allicin, 5-FU, and their combination were investigated using MTT assay in the 5-FU resistant MKN-45 gastric cells. According to our results, allicin and 5-FU exerted anticancer effects in a dose-dependent manner. The pretreatment with low-dose allicin has significantly increased the sensitivity of the chemoresistant GC cells to 5 -FU. Importantly, the $\mathrm{IC}_{50}$ value of co-treatment of allicin with 5 -FU was $49.46 \pm 10.61 \mu \mathrm{g} / \mathrm{ml}$ which lower than the $\mathrm{IC}_{50}$ values of 5 -FU alone $(164.52 \pm 1.92$ ) ( $\vee$ Fig.1,

$\checkmark$ Table 2) $(P<0.05)$.

\section{Co-treatment of allicin with 5-FU reduces the viability of gastric cancer cells}

Morphological assessment of apoptosis was carried out using DAPi. Pretreatment with allicin significantly increased apoptosis in 5-FU resistant GC cells. The formation of chromosomal DNA fragments and chromatin condensation was evident in the gastric cancer cells upon combination treatments. As presented in $>$ Fig. 2 , when the cells were grown in 5 -FU for $48 \mathrm{~h}$, the apoptotic percentage of MKN45 cells was $9.76 \pm 3.54$, whereas in allicin/5-FU treated cells the apoptotic rate was $19.11 \pm 5.19(P<0.05)$.

\section{Combination of allicin with 5-FU can alter the expression of $\mathrm{P}$-gp and CD44 proteins}

To confirm the results of allicin/5-FU induced apoptosis in the MKN45 cells, we further investigated whether allicin/5-FU can change $\mathrm{P}$-gp and CD44 protein expression by immunocytochemistry. Here, we found that P-gp expression was significantly decreased after treatment with allicin and allicin/5-FU when compared to control or 5-FU alone ( $\triangleright$ Fig. 3c-f) $(P<0.05)$. Interestingly, in the 5-FU resistant MKN-45 cell line where CD44 is overexpressed, allicin and allicin/5-FU decreased the CD44 expression compared to 5-FU and control ( $\vee$ Figure $4 \mathbf{c}, \mathbf{d})(P<0.05)$. In 5 -FU-treated cells, the percentage of CD44 expression was $42.29 \pm 6.8$, whereas, in allicinand allicin/5-FU-treated groups were $25.70 \pm 5.59$ and $25.06 \pm 1.8$, respectively.

\section{Efficacy of allicin, 5-FU, and their co-treatments on the expression of WNT5A and DKK1 mRNA level}

To investigate the inhibitory role of allicin/5-FU on the expression of MDR1, WNT5A, and DKK1, we pretreated the cells with $15 \mu \mathrm{g} / \mathrm{m}$ allicin, then the cells treated with a low dose 5-FU. According to our results, treatment with 5-FU, allicin, and allicin/5-FU down-regulated the expression of the DKK1 and MDR1 mRNA levels ( $\triangleright \mathbf{F i g . 5 a}$, b and $>$ Fig. 6). Moreover, we observed the down-regulation of WNT5A after treatment with allicin and allicin/5-FU.

\section{Discussion}

Our results demonstrated that a combination of allicin and 5-FU effectively decreased the growth of 5-FU resistant gastric cancer which is consistent with studies of osteosarcoma [20], hepatocellular cancer cells [15], and neuroblastoma cells [13]. Previously, we also demonstrated that allicin in combination with methylsulfonylmethane increased apoptosis and inhibited cell cycle in CD44 \pm breast cancer cells [21]. Jiang et al. found that the combined treatment of allicin with artesunate decreases the viability of osteosarcoma cells and suppresses the metastasis and colony formation ability through the overexpression of caspase-3/9 [20]. In another study, Gao et al. showed that the combined treatment of cyclophosphamide with allicin can improve T cell-mediated immunity and inhibit VEGF in neuroblastoma cells [11]. In a similar study, Zou et al. found that allicin enhanced anticancer activity of 5-FU by increasing reactive oxygen species (ROS) level and down-regulation of BCl-2 [15].

Our data showed a lower expression of P-gp, CD44 protein, and MDR1 mRNA expression after the combined treatment of allicin with 5-FU in GC. These reductions in CD44 and P-gp expression may suggest that pretreatment with allicin can reduce chemoresistance in gastric cancer cells. MDR genes and P-gp usually overexpress in $\mathrm{CD}_{4} 4^{+} / \mathrm{CD} 244^{-}$cancer cells. CD44 can interact with P-gp 

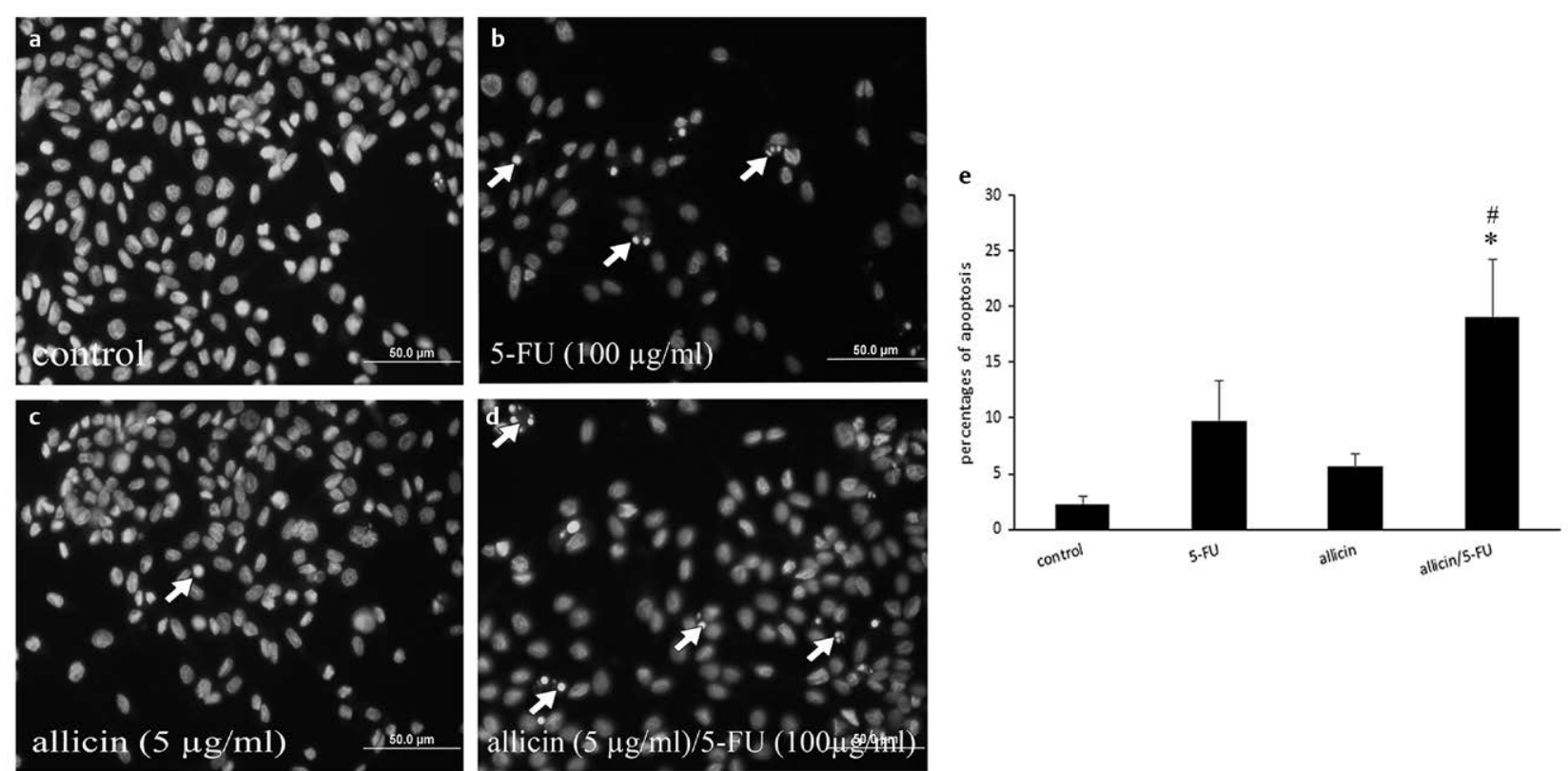

- Fig. 2 DAPi staining of 5-FU resistant gastric cancer treated with 5-FU (b), allicin (c), and allicin/5-FU. More apoptotic bodies (arrows) were seen after the combination treatments (d). ${ }^{*} p<0.05$ as compared to control cells. ${ }^{*} p<0.05$ as compared to 5 -FU treated cells. Scale bar $50 \mu \mathrm{M}$ (40X magnification).
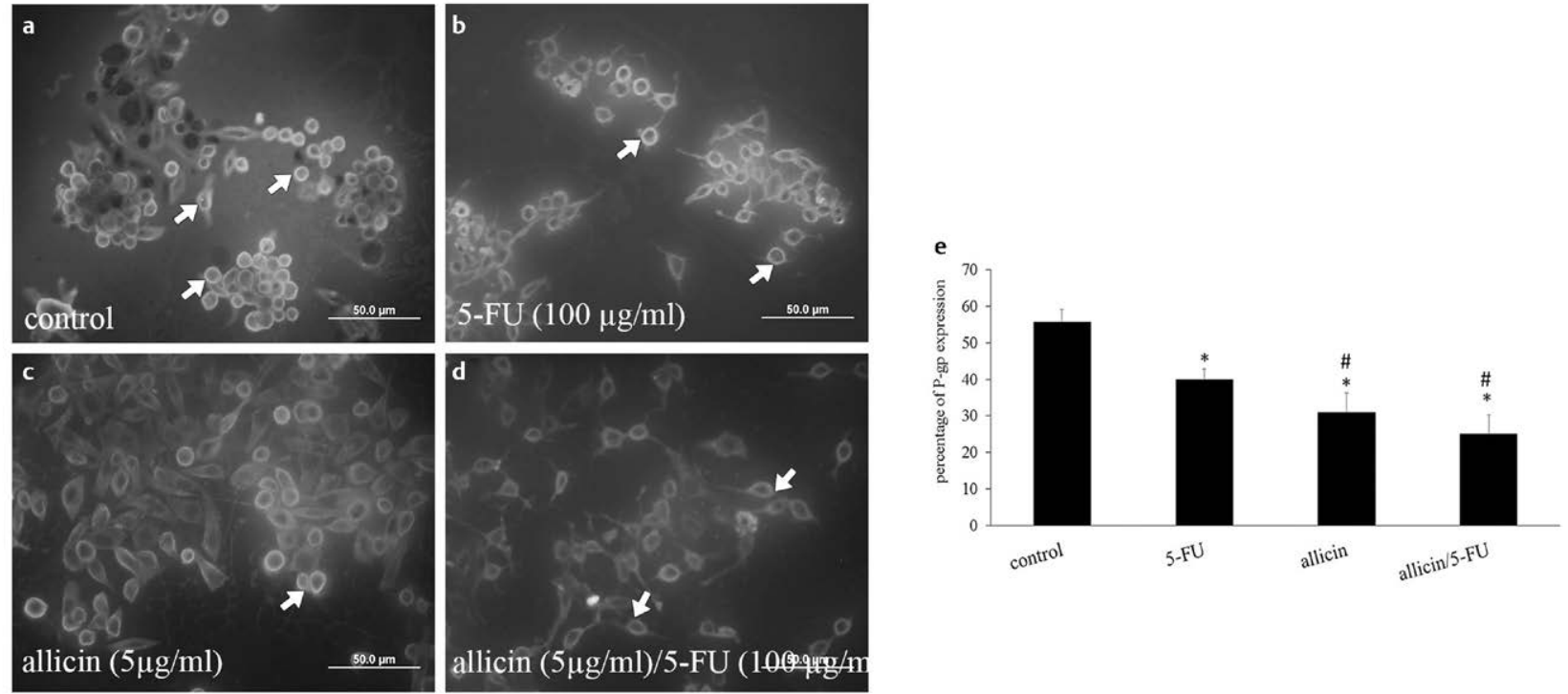

- Fig. 3 Immunocytochemical images show the expression of P-gp proteins in the gastric cancer cells treated with 5-FU (b), allicin (c), and co-treatment of allicin/5-FU (d). The arrows show cells expressing the P-gp protein. The expression of P-gp significantly decreased in all treated groups compared to control. Indeed, allicin and allicin/5-FU were more effective in decreasing the expression of P-gp compared to 5-FU alone (e). Data are expressed as mean \pm stdev. ${ }^{*} P<0.05$ as compared to the control group. ${ }^{\#} P<0.05$ as compared to the 5 -FU alone. Scale bar $50 \mu M$ ( $40 \mathrm{X}$ magnification).

to promote the invasion of cancer cells [22]. There is a link between the Wnt/ $\beta$-catenin pathway and P-gp. Recent studies have revealed that modulating of the $W n t / \beta$-catenin pathways may downregulate P-gp in cholangiocarcinoma [23]. The overexpression of MDR genes is associated with chemoresistance and a higher rate of systemic recurrence in GC patients [24]. In another study, Cha et al. showed that allicin can induce cell death in human glioma cells through inhibition of the MAPK/ERK-dependent pathway [25]. In 

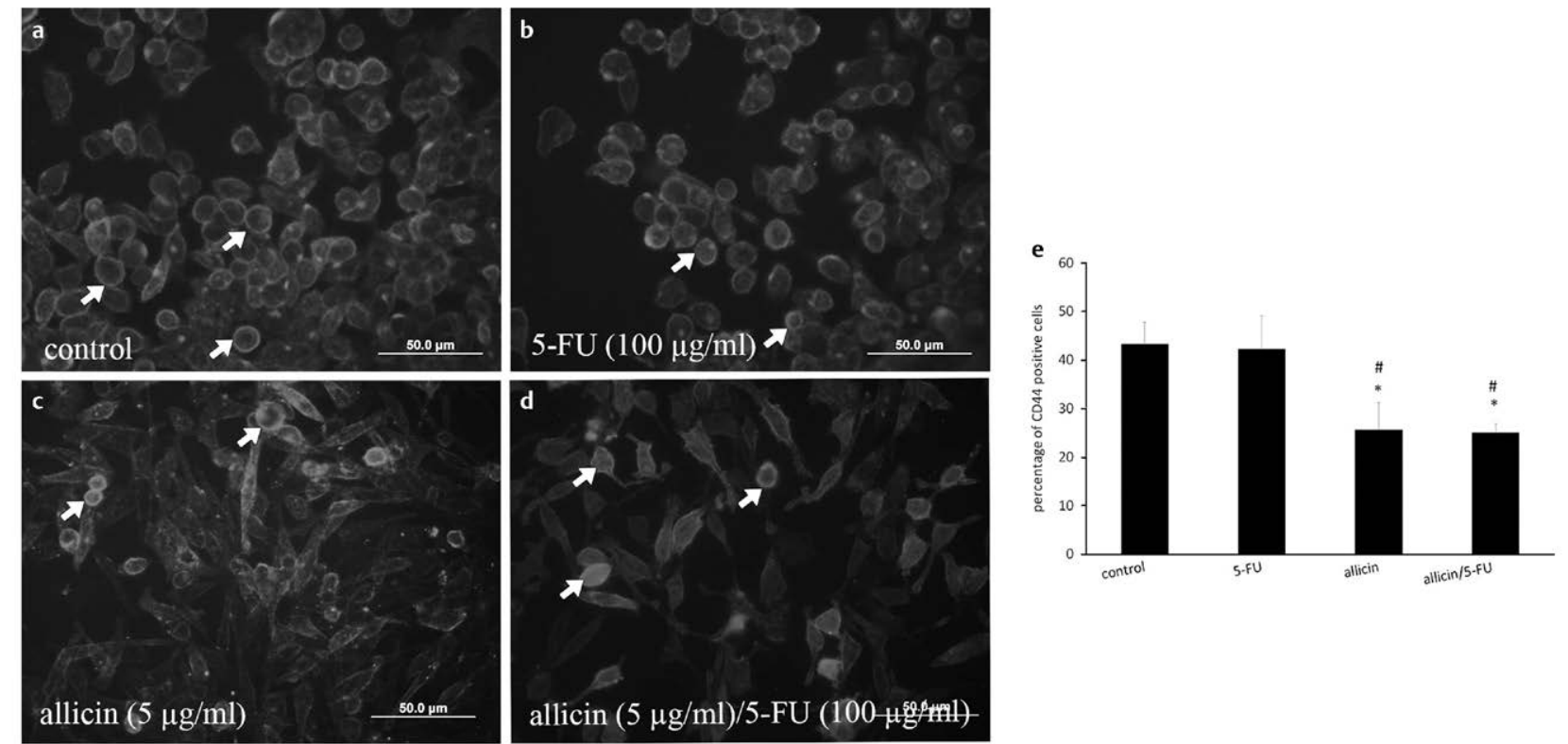

- Fig. 4 Immunocytochemical images show the expression of CD44 proteins in 5-FU resistant MKN-45 cells treated with 5-FU (b), allicin (c), and allicin/5-FU (d). Allicin and co-treatment of allicin and 5-FU were significantly decreased the expression of CD44 in gastric cancer (e). The arrows show the cells expressing CD44 protein. Data are expressed as mean \pm stdev. ${ }^{*} P<0.05$ as compared to the control. $\# P<0.05$ as compared to the 5 -FU. Scale bar $50 \mu \mathrm{M}$ (40X magnification).

a similar study, Wang et al. reported that diallyl trisulfide can increase cytotoxic effects of Adriamycin by downregulation of P-gp and NF-KB in human osteosarcoma [26]. The treatment of vinblastine-resistant leukemia K562 with a low dose of diallyl sulfide promotes the anticancer activity of vinblastine and reduces the expression of P-gp in chemoresistant leukemia cells [27]. Diallyl sulfide also suppresses MDR 1 gene expression by targeting the HOXC6mediated ERK1/2 signaling pathway [28]. In our previous study, we reported that the combination of allicin with all-trans retinoic acid inhibits $\mathrm{CD}_{4} 4^{+}$and $\mathrm{CD} 117^{+}$melanoma cells at $\mathrm{S}$ phases and induces the overexpression of cyclin D1 mRNA [12]. Therefore, these results demonstrated that co-treatment of allicin and 5-FU may inhibit the proliferation of chemoresistant gastric cancer cells by suppressing CD44 expressing cells.

Here, we observed the down-regulation of WNT5A and DKK1 after combined treatment with allicin and 5-FU. The Wnt signaling pathway has crucial functions during the development and metastasis of GC. It activates the non-canonical Wnt signaling pathway. Abnormal expression of the WNT5A gene was reported in $30 \%$ of GC cases. High expression of WNT5A is associated with a poor prognosis. WNT5A may behave as a tumor suppressor or a tumor-promoting agent in cancers $[29,30]$. DKK1 may act as a tumor suppressor or an oncogene in different cancers. Recently, Xu et al. have revealed that $S$-allyl cysteine, a garlic derivative, decreases the protein expression of WNT5A in human ovarian cancer cells [31]. Wang et al. demonstrated that overexpression of DKK1 suppresses the tumor-forming ability of CD44+ GC cells by modulating Wnt signaling [32]. In contrast, Lee et al. showed that increased levels of DKK1 in the serum of GC patients may act as an oncogene [33]. Moreover, Xia et al. reported that S-allyl-mercapto cysteine elevates DKK1 protein expression and decreases TCF/ $\beta$-catenin expres- sion in both Hep3B and Huh-7 hepatic cancer cell lines [34]. We conclude that allicin may alter the expression of DKK1 and WNT5A to restore the anticancer activity of 5-FU in chemoresistant GC.

In conclusion, our results demonstrated that the combined use of allicin with 5-FU could overcome chemoresistance by inhibiting the expression of MDR1, DKK1, WNT5A, CD44, and P-gp. Therefore, these in vitro observations strongly support that the use of lower dose allicin-based combinatorial chemotherapy has medical significance in GC patients.

\section{Author's Contributions}

NN conceived the idea and supervised the study. PK, MAV, and RP wrote the article and performed all the experiments, all authors contributed to final approval of the manuscript.

\section{Acknowledgment}

This study is a part of MSc thesis (IR.ARUMS.REC.1398.490) and a medical student research grant (IR.ARUMS.REC.1398.300) supported by Ardabil University of Medical Sciences. The authors would like to thank Mr. Farhad Pouremamali for gifting a 5-FU-resistant MKN-45 gastric cancer cell line.

\section{Conflict of Interest}

All authors declare that they have no conflict of interest. 

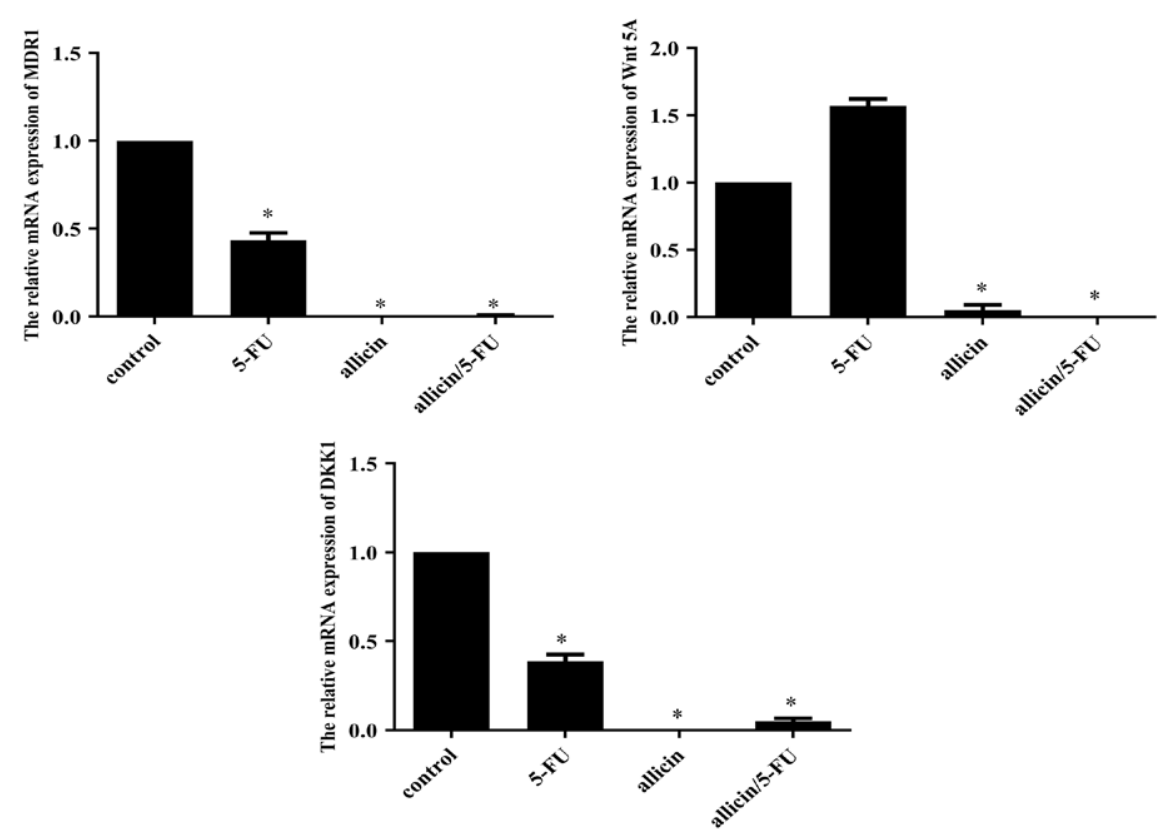

> Fig. 5 The mRNA expression level of MDR1, DKK1, and WNT5A determined in 5-FU $(\mu \mathrm{g} / \mathrm{ml})$, allicin $(\mu \mathrm{g} / \mathrm{ml})$, and allicin $/ 5$-FU treated 5-FU resistant MKN-45 gastric cancer cells. ${ }^{*} P<0.05$ as compared to control.

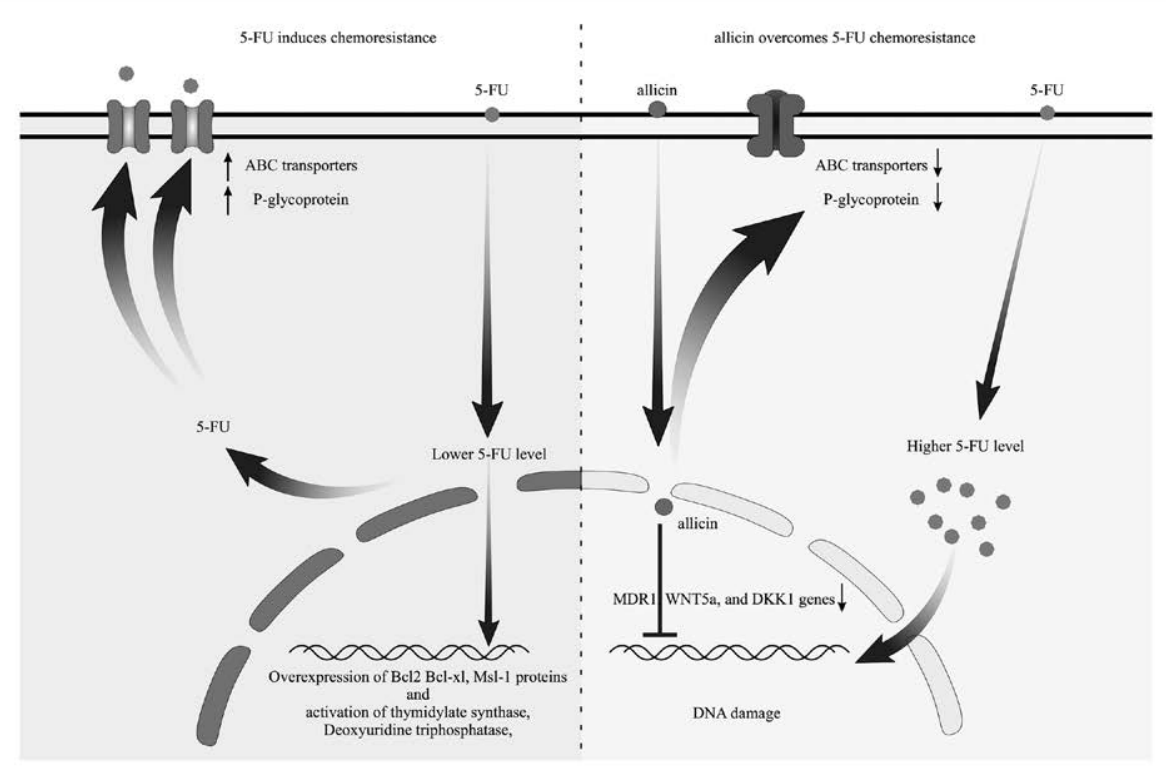

> Fig. 6 Schematic diagram showing 5-FU-chemoresistance and possible action of allicin on gastric cancer.

\section{References}

[1] Bray F, Ferlay J, Soerjomataram I et al. Global cancer statistics 2018: GLOBOCAN estimates of incidence and mortality worldwide for 36 cancers in 185 countries. CA Cancer J Clin 2018; 68: 394-424 doi:10.3322/caac.21492.
[2] Fitzmaurice C, Akinyemiju TF, Al Lami FH et al. Global, regional, and national cancer incidence, mortality, years of life lost, years lived with disability, and disability-adjusted life-years for 29 cancer groups, 1990 to 2016: A systematic analysis for the global burden of disease study. JAMA oncology 2018; 4: 1553-1568

[3] Van Cutsem E, Sagaert X, Topal B et al. Gastric cancer. The Lancet 2016; 388: 2654-2664 
[4] Van Cutsem E, Moiseyenko VM, Tjulandin S et al. Phase III study of docetaxel and cisplatin plus fluorouracil compared with cisplatin and fluorouracil as first-line therapy for advanced gastric cancer: A report of the V325 Study Group. J Clin Oncol 2006; 24: 4991-4997

[5] Shi W-J, Gao J-B. Molecular mechanisms of chemoresistance in gastric cancer. World J Gastrointest Oncol 2016; 8: 673-681. doi:10.4251/ wjgo.v8.i9.673

[6] Mansoori B, Mohammadi A, Davudian S et al. The different mechanisms of cancer drug resistance: A brief review. Advanced Pharmaceutical Bulletin 2017; 7: 339

[7] Wei W, Sun HH, Li N et al. WNT5A modulates cell cycle progression and contributes to the chemoresistance in pancreatic cancer cells. Hepatobiliary \& Pancreatic Diseases International : HBPD INT 2014; 13 : 529-538. doi:10.1016/s1499-3872(14)60277-0

[8] Aguilera Ó, González-Sancho JM, Zazo S et al. Nuclear DICKKOPF-1 as a biomarker of chemoresistance and poor clinical outcome in colorectal cancer. Oncotarget 2015; 6: 5903

[9] Demaria M, O'Leary MN, Chang J et al. Cellular senescence promotes adverse effects of chemotherapy and cancer relapse. Cancer Discovery 2017; 7: 165-176

[10] Jiang W, Huang Y, Wang J-P et al. The synergistic anticancer effect of artesunate combined with allicin in osteosarcoma cell line in vitro and in vivo. Asian Pacific Journal of Cancer Prevention 2013; 14: 46154619

[11] Gao X-Y, Geng X-J, Zhai W-L et al. Effect of combined treatment with cyclophosphamidum and allicin on neuroblastoma-bearing mice. Asian Pac J Trop Med 2015; 8: 137-141

[12] Mohammadi Jobani B, Najafzadeh N, Mazani M et al. Molecular mechanism and cytotoxicity of allicin and all-trans retinoic acid against CD44 + versus CD117 + melanoma cells. Phytomedicine 2018; 48: 161-169

[13] Țigu AB, Toma V-A, Moț AC et al. The Synergistic Antitumor Effect of 5-Fluorouracil Combined with Allicin against Lung and Colorectal Carcinoma Cells. Molecules 2020; 25: 1947

[14] Zhang W, Ha M, Gong Y et al. Allicin induces apoptosis in gastric cancer cells through activation of both extrinsic and intrinsic pathways. Oncology Reports 2010; 24: 1585-1592

[15] Zou X, Liang J, Sun J et al. Allicin sensitizes hepatocellular cancer cells to anti-tumor activity of 5 -fluorouracil through ROS-mediated mitochondrial pathway. Journal of Pharmacological Sciences 2016; 131: $233-240$

[16] Pouremamali F, Jeddi F, Samadi N. Nrf2-ME-1 axis is associated with 5-FU resistance in gastric cancer cell line. Process Biochemistry 2020

[17] Mokabber H, Najafzadeh N, Mohammadzadeh Vardin M. miR-124 promotes neural differentiation in mouse bulge stem cells by repressing Ptbp1 and Sox9. J Cell Physiol 2019; 234: 8941-8950. doi:10.1002/jcp.27563

[18] Fatehi-Agdam M, Vatankhah MA, Panahizadeh R et al. Efficacy of Metformin and Chemotherapeutic Agents on the Inhibition of Colony Formation and Shh/Gli1 Pathway: Metformin/Docetaxel Versus Metformin/5-Fluorouracil. Drug Research 2021; 71: 17-25
[19] Mohammadi Jobani B, Mohebi E, Najafzadeh N. In Vitro Anticancer Effects of All-trans Retinoic Acid in Combination with Dacarbazine against CD117 + Melanoma Cells. Drug Research 2020; 70: 563-569

[20] Jiang W, Huang Y, Wang J-P et al. The synergistic anticancer effect of artesunate combined with allicin in osteosarcoma cell line in vitro and in vivo. Asian Pac J Cancer Prev 2013; 14: 4615-4619

[21] Sarkhani E, Najafzadeh N, Tata N et al. Molecular mechanisms of methylsulfonylmethane and allicin in the inhibition of CD44 \pm breast cancer cells growth. Journal of functional foods 2017; 39: 50-57

[22] Wright MH, Calcagno AM, Salcido CD et al. Brca1 breast tumors contain distinct CD44 $+/ C D 24$-and CD133 + cells with cancer stem cell characteristics. Breast Cancer Research 2008; 10: R10

[23] Shen DY, Zhang W, Zeng $X$ et al. Inhibition of Wnt/ $\beta$-catenin signaling downregulates P-glycoprotein and reverses multi-drug resistance of cholangiocarcinoma. Cancer Science 2013; 104: 1303-1308

[24] Chung HC, Gong SJ, Yoo NC et al. P-glycoprotein as an intermediate end point of drug resistance to neoadjuvant chemotherapy in locally advanced gastric cancer. Yonsei Medical Journal 1996; 37: 397-404

[25] Cha JH, Choi YJ, Cha SH et al. Allicin inhibits cell growth and induces apoptosis in U87MG human glioblastoma cells through an ERK-dependent pathway. Oncology Reports 2012; 28: 41-48

[26] Wang Z, Xia Q, Cui J et al. Reversion of P-glycoprotein-mediated multidrug resistance by diallyl trisulfide in a human osteosarcoma cell line. Oncology Reports 2014; 31: 2720-2726

[27] Arora A, Seth K, Shukla Y. Reversal of P-glycoprotein-mediated multidrug resistance by diallyl sulfide in $\mathrm{K} 562$ leukemic cells and in mouse liver. Carcinogenesis 2004; 25: 941-949. doi:10.1093/carcin/ bgh060

[28] Jeong YS, Lam TG, Jeong S et al. Metformin Derivative HL156A Reverses Multidrug Resistance by Inhibiting HOXC6/ERK1/2 Signaling in Multidrug-Resistant Human Cancer Cells. Pharmaceuticals 2020; 13: 218

[29] Astudillo P. Wnt5a signaling in gastric cancer. Frontiers in Cell and Developmental Biology 2020; 8: 110

[30] Hong SA, Yoo SH, Lee HH et al. Prognostic value of Dickkopf-1 and ss-catenin expression in advanced gastric cancer. BMC Cancer 2018; 18: 506

[31] Xu Y-s, Feng J-g, Zhang D et al. S-allylcysteine, a garlic derivative, suppresses proliferation and induces apoptosis in human ovarian cancer cells in vitro. Acta Pharmacologica Sinica 2014; 35: 267-274

[32] Wang B, Liu J, Ma LN et al. Chimeric 5/35 adenovirus-mediated Dickkopf-1 overexpression suppressed tumorigenicity of CD44 + gastric cancer cells via attenuating Wnt signaling. Journal of Gastroenterology 2013; 48: 798-808

[33] Lee HS, Lee HE, Park D] et al. Clinical significance of serum and tissue Dickkopf- 1 levels in patients with gastric cancer. Clinica Chimica Acta 2012; 413: 1753-1760

[34] Xiao ], Xing F, Liu Y et al. Garlic-derived compound S-allylmercaptocysteine inhibits hepatocarcinogenesis through targeting LRP6/Wnt pathway. Acta Pharmaceutica Sinica B 2018; 8: 575-586 